\title{
Humus condition under different systems of basic cultivation of dark gray forest soil
}

\author{
Nikolay Perfilyev*, Olga Vyushina \\ Tyumen Scientific Center of the Siberian Branch of the Russian Academy of Sciences, 86 Malygina \\ St., 625026 Tyumen, Russia
}

\begin{abstract}
Studies, were conducted in a stationary experiment between 1988 and 2018 on dark gray forest heavy loam soil in Scientific Research Institute of Agriculture for Northern Trans-Ural Region - Branch of Federal State Institutions Federal Research Centre Tyumen Scientific Centre of Siberian Branch of the Russian Academy of Sciences. The aim of the study is to determine the effect of long-term ( 30 years) impact of different systems of basic cultivation of dark gray forest soils in the cultivation of grain crops on the humus content. Observations were made according to generally accepted methods during 6 rotations of grain and fallow crop rotation: bare fallow, winter rye, spring wheat, spring vetch, spring barley, unfolded in time and space. The impact of the combined system of tillage with alternation of plowing and no-tillage at $20-22 \mathrm{~cm}$ during 6 rotations of a 5-pole grain and steam crop rotation (30 years), increased the humus content in the $0-40 \mathrm{~cm}$ layer of dark gray forest soil compared with the initial content by $0.42 \%$. The systems of main tillage differentiated, without sowing, and mouldboard provided in general a relatively favorable dynamics of the humus state of the soil. The content of humus in the $0-40 \mathrm{~cm}$ layer of soil by differentiated and unswept systems during the study period remained close to the initial condition. По отвальной системе содержание гумуса снижалось на $0,22 \%$ или в среднем $0,37 \mathrm{~T} /$ га в год. The greatest loss of humus in the $0-40 \mathrm{~cm}$ layer of soil by $0.80 \%$ in relation to the initial was the impact of surface treatment with annual discing BDT-2,5 (heavy disc harrows) on 10-12 $\mathrm{cm}$ or an average annual loss of $1.33 \mathrm{t} /$ ha.
\end{abstract}

\section{Introduction}

Tillage systems, having a direct impact on soil composting. The distribution of organic residues on soil horizons, largely affect the elements of effective and potential fertility, on the humus state of soils, by which mainly assess the state of soil fertility [1-4]. Indeed, the quality of soil structure, the formation of the soil profile, the provision of soil with nutrients depends on humus [5]. At the same time, nutrients, mainly nitrogen, become available to plants in the process of humus mineralization [6]. During the cultivation of agricultural plants, partial replenishment of soil humus occurs due to the arrival of crop and root

\footnotetext{
${ }^{*}$ Corresponding author: p.nikolay52@yandex.ru
} 
residues in the process of their mineralization and humification. The degree of intensity of these processes is also largely determined by the method of tillage [7,8].

Numerous studies in our country and abroad have established that during the agricultural use of arable land on modern farming systems, there is mainly a decrease in soil fertility, reducing the content of organic matter in the soil $[9,10]$.

According to L.N. Karetin, the use of dark gray forest soils in the Northern Trans-Urals Region led to a decrease in humus content from 5-6 to 3-4\% for 45-50 years in arable land [11]. The causes of dehumification, along with insufficient levels of organic and mineral fertilizers, and the violation of fertility change, are also caused by insufficient consideration of zonal features in soil treatment $[12,13]$.

However, research data on the impact of tillage systems and techniques on the state of humus are contradictory. This is due to differences in natural-climatic and soil conditions, the set of crops in crop rotations, the level of organic and mineral fertilizers, as well as different duration of the impact of the studied methods of treatment.

Thus, the positive effect of no-tillage on the humus state in the studies is explained by modeling of the sod formation process $[14,15]$. In other studies, the increase in humus content with minimization of the main tillage is explained by a decrease in the intensity of mineralization of crop residues, root residues, and organic fertilizers. And the loss of humus by plowing, on the contrary, increasing the level of mineralization. [16].

In the literature, some researchers explain the positive effect of no-tillage and minimum tillage by the more favorable conditions of water and temperature regime for humification of plant residues [17]. Publications also contain data on the negative effect of minimum tillage on humus formation, which can be explained by a more intensive mineralization of organic matter in the upper soil layers [18].

At the same time, the decrease in humus content in shallow tillage, especially in the lower soil horizons, is linked to the lack of organic matter entering the deeper soil layers, where humification usually takes place.

At the same time, there is evidence that the content of humus in the soil in the absence of erosion processes in the conditions of traditional technologies is quite stable. Despite quite significant fluctuations from year to year, it remains at the same level, and the identified difference between the variants of the treatment systems is associated with the heterogeneity of fertility of the experimental plot [19].

For the conditions of the Northern Trans-Ural Mountains, the effect of different tillage systems, especially with their prolonged impact on the humus content in dark gray forest soils has not been studied sufficiently.

The aim of the studies was to determine the effect of long-term (30 years) impact of different systems of basic cultivation on the content of humus in dark gray forest soils.

\section{Materials and Methods}

Studies were conducted in a stationary experiment on the experimental field Scientific Research Institute of Agriculture for Northern Trans-Ural Region - Branch of Federal State Institutions Federal Research Centre Tyumen Scientific Centre of Siberian Branch of the Russian Academy of Sciences in 1988-2018 during 6 rotations of the grain and fallow crop rotation: bare fallow, winter rye, spring wheat, spring vetch, and spring barley, deployed in time and space. Soil is dark gray forest, heavy loam. Depth of humus horizon is $25-27 \mathrm{~cm}$, humus content for the period of laying the experiment in $0-20 \mathrm{~cm}$ layer is $2.32-3.90 \%, \mathrm{pH}$ of salt extract is 6.0-6.4. Amount of absorbed bases in arable layer 18.6-25.6 mg/eq. per $100 \mathrm{~g}$ of soil.

The systems of tillage were studied: ploughed - annually for all crops plowing with Lemken reversible plow on 20-22 cm; non-shafted - annually plowing with SibIME (plow 
designed by the Siberian Research Institute of Mechanization and Electrification) stands on 20-22 cm; combined - alternation of plowing and non-shaft loosening on 20-22 cm; differentiated - in fallow and after winter rye plowing Smaragd (flat tillage cultivator) on 12-14 cm, plowing Lemken on 20-22 cm for spring vetch, under barley and after it - discing BDT-2,5 (heavy disc harrows) on 10-12 cm combined-minimal alternating plowing at 20$22 \mathrm{~cm}$ and discing BDT-2.5 at 10-12 cm; alternating ripping with SibME stands at 20-22 $\mathrm{cm}$ and discing BDT-2.5 at 10-12 cm; alternating plowing at 20-22 cm and ripping with Smaragd at 12-14 cm; ploughing - annual treatment with Smaragd at 12-14 cm; surface annual treatment with BDT-2.5 at $10-12 \mathrm{~cm}$.

In spring, on all backgrounds of the main treatment was carried out conventional presowing treatment and seeding with SZP-3,6 (grain-press seeder, working width 3.6 meters). Fertilizers were applied before sowing at the rate of $\mathrm{N}_{40} \mathrm{P}_{40} \mathrm{~K}_{40} \mathrm{~kg}$. a.i. per 1 ha of crop area, on the background without fertilizers they were not applied. Treatment with herbicides general background. Generally accepted methods were used in the studies [20].

\section{Results and discussion}

According to our studies, the initial humus content in 1988 in the arable layer of the experimental plot varied from 2.32 to $3.27 \%$ (Table 1), which according to the classification of soil types by humus content corresponds to low-humus (1.5-3.0\%) and lower gradation of medium-humus (3.0-5.0\%) soils.

Table 1. Humus content depending on the systems of main tillage in the grain and fallow crop rotation

\begin{tabular}{|c|c|c|c|c|c|c|}
\hline \multirow{2}{*}{ Option of experience } & \multirow{2}{*}{ Years } & \multicolumn{5}{|c|}{ Soil layer, $\mathrm{cm}$} \\
\hline & & $0-10$ & $10-20$ & $20-40$ & $0-20$ & $0-40$ \\
\hline \multirow{2}{*}{$\begin{array}{c}\text { Dumping ground, } \\
\text { plow Lemken at } 20- \\
22 \mathrm{~cm}\end{array}$} & $1988^{*}$ & 3,28 & 3,26 & 2,64 & 3,27 & 3,06 \\
\hline & $2018^{* *}$ & 3,02 & 3,40 & 2,10 & 3,21 & 2,84 \\
\hline \multirow{2}{*}{$\begin{array}{c}\text { Shoeless, } \\
\text { plow LP-0.35 at } 20- \\
22 \mathrm{~cm}\end{array}$} & 1988 & 3,36 & 2,92 & 1,72 & 3,14 & 2,67 \\
\hline & 2018 & 3,22 & 2,74 & 2,27 & 2,98 & 2,74 \\
\hline \multirow{2}{*}{$\begin{array}{c}\text { Combined, plow LP- } \\
0.35 \\
\text { by } 20-22 \mathrm{~cm}\end{array}$} & 1988 & 2,40 & 2,24 & 1,17 & 2,32 & 1,94 \\
\hline & 2018 & 2,86 & 2,80 & 1,43 & 2,83 & 2,36 \\
\hline \multirow{2}{*}{$\begin{array}{l}\text { Differentiated, BDT- } \\
2.5 \text { (heavy disc } \\
\text { harrows) } \\
\text { at } 10-12 \mathrm{~cm}\end{array}$} & 1988 & 2,75 & 2,63 & 1,39 & 2,69 & 2,26 \\
\hline & 2018 & 3,22 & 2,74 & 0,82 & 2,98 & 2,26 \\
\hline \multirow{2}{*}{$\begin{array}{c}\text { Superficial, BDT- } \\
2.5 \\
\text { (heavy disc harrows) } \\
\text { by } 10-12 \mathrm{~cm}\end{array}$} & 1988 & 3,28 & 3,26 & 2,64 & 3,27 & 3,06 \\
\hline & 2018 & 2,56 & 2,26 & 1,97 & 2,41 & 2,26 \\
\hline \multirow{2}{*}{$\begin{array}{l}\text { Flat cut, Smaragd } \\
\text { (flat tillage } \\
\text { cultivator) } \\
\text { at } 12-14 \mathrm{~cm} \\
\end{array}$} & 1988 & 3,36 & 2,92 & 1,72 & 3,14 & 2,67 \\
\hline & 2018 & 3,50 & 2,98 & 0,43 & 3,24 & 2,30 \\
\hline $\mathrm{NCR}_{05}$ & & 0,15 & 0,17 & 0,24 & 0,17 & 0,29 \\
\hline
\end{tabular}

$1988 *$ - original, $2018 * *$ - completion of 6 th rotation

According to the classification (Orlov et al., 2004), the content of humus corresponded to a low level (2-4\%) [21]. During the study period during the 6 rotations of crop rotation, 
the state of soil humus content in the experimental plot remained mostly at the baseline level. Thus, the content of humus in the arable layer in 2018 was $2.41-3.24 \%$, which also corresponded to a low level.

To assess the increase or decrease in humus content between the studied treatment variants in absolute values under the conditions of spatial remoteness of plots, natural heterogeneity of soil fertility, differences in their initial content of humus in the soil is not quite correct. Therefore, we evaluated the effect of treatment systems on the change in humus content by comparing the intensity of changes in its content in relation to the initial condition in each of the studied treatment variants.

In our studies, the most effective in terms of preservation of soil fertility proved to be a combined system of main tillage with alternation in the years of mouldboard and no-till tillage to a depth of $20-22 \mathrm{~cm}$. As a result of using the combined system of cultivation during 6 rotations of the crop rotation the humus content in the layer $0-20 \mathrm{~cm}$ increased in comparison with the initial state by $0,51 \%$ or by $12,24 \mathrm{t} / \mathrm{ha}$. In the soil layer $0-40 \mathrm{~cm}$ by $0.42 \%$ or $21.0 \mathrm{t} / \mathrm{ha}$, with an average annual increase of $0.014 \%$ or $0.7 \mathrm{t} / \mathrm{ha}$. This is explained by the fact that under this system of cultivation, due to periodic stocking of organic stubble and root residues, as well as humified compounds from the upper layer of soil to the lower horizons more steadily provided with moisture, the following year in anaerobic conditions reduces the activity of decomposition of these organic residues, and conversely, conditions are created for their humification.

The content of humus at the mouldboard system of cultivation during the 6 rotations of the rotation remained quite stable with some fluctuations in the rotations of the rotation. Thus, in the tilled $0-20 \mathrm{~cm}$ layer the decrease in humus content by the end of the 6 th rotation of the rotation was $0.06 \%(1.44 \mathrm{t} / \mathrm{ha})$. In the $0-40 \mathrm{~cm}$ layer of soil humus content decreased in comparison with the initial by $0.22 \%$ or $11.0 \mathrm{t} / \mathrm{ha}$, with a decrease in the average annual content by $0.007 \%$ or $0.36 \mathrm{t} / \mathrm{ha}$. This was due to a decrease in humus content in the soil layer $0-10 \mathrm{~cm}$ by $0.26 \%$, in the soil layer $20-40 \mathrm{~cm}$ by $0.54 \%$, while in the soil layer $10-20 \mathrm{~cm}$ there was an increase in humus content of $0.14 \%$.

In the cultivation of cereals with the use of no-tillage and differentiated systems of tillage the state of humus for the 30 -year period of observation has not changed. Thus, at differentiated system of tillage there was $0,47 \%$ increase of humus content in $0-10 \mathrm{~cm}$ layer and $0,11-0,57 \%$ decrease in $10-20 \mathrm{~cm}$ and $20-40 \mathrm{~cm}$ layer; in general, $0-40 \mathrm{~cm}$ layer humus content was the same as initial $-2,26 \%$. Under no-tillage system of cultivation the increase in humus content in $0-40 \mathrm{~cm}$ layer was $0.07 \%$ or $3.50 \mathrm{t} / \mathrm{ha}$, with an average annual increase of $0.12 \mathrm{t} / \mathrm{ha}$. Under flat-cutting system of cultivation - annual cultivation to the depth of 12 $14 \mathrm{~cm}$ was carried out without wrapping the topsoil. Therefore, plant residues were concentrated in the upper soil layer, as a result, during the years of research the humus condition of the $0-20 \mathrm{~cm}$ soil layer remained almost unchanged compared to the initial content, with a slight increase of $0.10 \%$ in relation to it.

At the same time, there was an impoverishment of organic matter in the $20-40 \mathrm{~cm}$ layer, as a result, the content of humus in it decreased by $1.29 \%$ in relation to the initial content in this layer. On the whole on the $0-40 \mathrm{~cm}$ layer of soil the decrease in humus content by the flat tillage system was $0.37 \%$ or $18.5 \mathrm{t} / \mathrm{ha}$. The average annual decrease was $0.012 \%$ or 0.62 t/ha.

According to our data, of all the studied systems of cultivation, the most significant loss of humus was noted in the variant of surface system of cultivation with annual cultivation by discing BDT-2.5 to a depth of 10-12 cm. Reduction of humus content in the $0-40 \mathrm{~cm}$ layer was $0.80 \%$ or $40 \mathrm{t} / \mathrm{ha}$ in relation to the initial one. The average annual decrease was $0.027 \%$ or $1.33 \mathrm{t} / \mathrm{ha}$. Decrease in humus content in the upper $0-10 \mathrm{~cm}$ layer by $0.72 \%$, is explained by increased mineralization of organic plant and root residues concentrated in the surface soil layer. Decrease of its content in lower layers - in 10-20 cm layer by $1,00 \%$ in 
$20-40 \mathrm{~cm}$ layer by $0,67 \%$ can be explained by absence of significant receipt of organic residues in them and expenditure of humus reserves available in them for plant nutrition.

\section{Conclusions}

1. Application of the combined system of tillage with alternation of plowing and subsurface tillage at 20-22 cm during 6 rotations of a 5-pole grain and fallow crop rotation (30 years), increased the humus content in $0-40 \mathrm{~cm}$ layer of dark gray forest soil compared with the initial content by $0.42 \%$.

2. The systems of main tillage: differentiated, without sowing, and mouldboard provided in general a relatively favorable dynamics of the humus state of the soil. The content of humus in the $0-40 \mathrm{~cm}$ layer of soil by differentiated and unswept systems remained close to the initial state during the study period. Under the mouldboard system, the content of humus decreased by $0.22 \%$ or an average of $0.37 \mathrm{t} / \mathrm{ha}$ per year.

3. The greatest loss of humus in the $0-40 \mathrm{~cm}$ layer of the soil by $0.80 \%$ or an average annual loss of $1.33 \mathrm{t} / \mathrm{ha}$ relative to the initial content was when using the surface treatment system with annual discing BDT-2.5 on $10-12 \mathrm{~cm}$.

\section{Acknowledgment}

Work performed under the state order No 121041600037-3 .

\section{References}

1. M.A. Mazirov, N.S. Matyuk, V.D. Polin, N.V. Malakhov, Farming, 2, 33-36 (2018) DOI:10.24411/0044-3913-2018-10208

2. Jumana Al-Mallahi, Ragheb Tahhan, Sa'eb Khresat, Eurasian Journal of Soil Science, 9 (3) 222-230 (2020) DOI:10.18393/ejss.728435

3. Akhmetzyanov Marsel Ravilovich, Khuzina Gulina Kutdusovna, Talanov Ivan Pavlovich, Vestnik of Kazan GAU, $T \quad 14 \quad \mathbf{1}$ (52), $11-16 \quad$ (2019) DOI:10.12737/article_5cbf071db935c2.43706278

4. A.R. Valiev, Proceedings of the visiting meeting of the Bureau of the section of mechanization, electrification and automation, Department of Agricultural Sciences of RAS. - Kazan: Publishing house of Kazan State Agrarian University, 143-151 (2015)

5. D. I. Eremin, Eurasian Soil Sc., 49, 538-545 (2016) DOI:10.1134/S1064229316050033

6. V.V. Kidin, A.E. Shibalkin, M.V. Kagirova, Eurasian J. Soil Science, 8 (2), 167-175 (2019) DOI: 10.18393 / ejss.551268

7. Olson, K.R., Gennadiev, A.N., Eurasian Soil Sc., 53, 436-445 (2020) DOI: 10.1134/S1064229320040122

8. D.I. Eremin, A.A. Akhtyamova, Farming, 7, 16-18 (2018) DOI:10.24411/0044-39132018-10704

9. V.I. Usenko, S.V. Usenko, T.A. Litvinova, Farming, 6, 18-20 (2020) DOI:10.24411/0044-3913-2020-10604

10. V.N. Semenov, B.M. Kogut, M.: GEOS, 233 (2015)

11. L.N. Karetin, Novosibirsk: Nauka. Siberian Branch, 258 (1990)

12. T.A. Trofimova, S.I. Korzhov, A.P. Pichugina, G.V. Kotov, Vestnik of Voronezh State Agrarian University, 3(50), 32-39 (2016) DOI:10.17238/issn2071-2243.2016.3.32 
13. A.N. Vlasenko, P.I. Kudashkin, N.G. Vlasenko, Farming, 5, 3-6 (2020) DOI:10.24411/0044-3913-2020-10501

14. Meiling Man ClaudiaWagner-Riddle Kari E.Dunfield BillDeen Myrna J.Simpson, Soil and Tillage Research, 209, 104960 (2021) DOI:10.1016/j.still.2021.104960

15. V.V. Okorkov, O.A. Fenova, L.A. Okorkova, Agrochemistry, 1, 17-26 (2016)

16. Götze P., Rücknagel J., Holzweißig B., Steinz M., Christen O., Jacobs A., Märländer B., Koch H.-J., European Journal of Agronomy, T 76, 198-207 (2016)

17. D.V. Dubovik, E.V. Dubovik, A.V. Shumakov, B.S. Ilyin, Agrochemistry, 3, 22-27 (2021) DOI:10.31857/S0002188121030066

18. Haddaway, N.R., Hedlund, K., Jackson, L.E.et al., A systematic review protocol. Environ Evid 5, 1 (2016). DOI:10.1186/s13750-016-0052-0

19. M.A. Glukhikh, A.A. Kolganova, Vestnik of the Orenburg State University, 12 (212), 4-6 (2017)

20. V.D. Luganskaya, V.N. Lugansky, method. instructions, Editorial and publishing department of UGLTU, 29 (2011)

21. D.S. Orlov, O.N. Biryukova, M.S. Rozanova, Soil Science, 8, 918-926 (2004) 